\title{
REVIEW
}

\section{Evaluation of the azoospermic male}

\author{
Robert Oates
}

When presented with an azoospermic patient, a thorough history and careful, considered physical examination often leads to a definite or presumptive diagnosis. An algorithmic, logical thought process is important to have in mind when embarking on the evaluation. Adjunctive laboratory tests, such as hormonal assays or genetic studies, are often complementary and/or additive and allow a very precise determination to be made as to the etiologies, either genetic or acquired. It is only with this information that a therapeutic plan can be made for the patient. As will be discussed, a targeted approach to testing is far more satisfying and cost-effective than a blind, shotgun approach.

Asian Journal of Andrology (2012) 14, 82-87; doi:10.1038/aja.2011.60; published online 19 December 2011

Keywords: azoospermia; congenital bilateral absence of the vas deferens; male infertility; Y chromosomal microdeletion

\section{INTRODUCTION}

In most circumstances, azoospermia is diagnosed when no spermatozoa are detected upon microscopic evaluation of two centrifuged semen samples. As will be seen below, certain conditions only require a single semen specimen when coupled with history, physical examination or both. Azoospermia is found in approximately $1 \%$ of all men and up to $15 \%$ of infertile men, depending upon the demographic nature of the infertile cohort. ${ }^{1}$ Aspermia is defined as a complete absence of seminal fluid during orgasm. Men with azoospermia should be evaluated in an effort to discover the underlying etiology of their condition, which will guide the formulation of a therapeutic plan. ${ }^{2}$ A complete history and physical examination is mandatory, while measurement of reproductive hormones (testosterone, folliclestimulating hormone (FSH), luteinizing hormone ( $\mathrm{LH})$, prolactin and estradiol) are potentially helpful. Depending upon the certain or suspected diagnosis, a Y chromosomal microdeletion assay, a karyotype, cystic fibrosis mutation analysis, transrectal ultrasonography and renal ultrasonography may be helpful. There should be no single 'azoospermia panel' where all of these studies are ordered in a shotgun approach with no regard to the likely diagnosis. These adjunctive tests are ordered in a targeted way-only those that are necessary based upon the presumptive diagnosis are obtained. This presumptive diagnosis is arrived at by the evaluating clinician with a combination of the mind (what do the history, the semen analysis and the hormonal data suggest), the eyes (what does the patient's appearance suggest) and the fingers (what does the genital physical examination suggest). To be clear in one's thoughts, though, it requires a way of thinking about azoospermia, a process to focus on and an algorithm to follow.

\section{AZOOSPERMIA: HOW DO WE BEGIN TO DETERMINE THE DIAGNOSIS?}

There are two algorithmic ways to think about the etiology of azoospermia. To find the cause is imperative, whether it is obstructive, non-obstructive, congenital (genetic) or acquired as it informs the patient and his partner in regard to other health issues which he may need to contend with, in regard to the best treatment strategies to help them achieve pregnancy and in regard to what genetic anomalies might be passed along to any conceived offspring.

The first approach is based on where, anatomically and physiologically, the primary problem is within the hypothalamic-pituitary-gonadal axis (see Krausz for a review using this paradigm ${ }^{3}$ ). 'Pre-testicular' azoospermia arises when the hypothalamus and pituitary are not functioning properly to stimulate intrinsically normal testes in terms of both gonadal functions - testosterone synthesis in the Leydig cells and spermatogenesis within the seminiferous tubules. 'Testicular' azoospermia occurs when the hypothalamus and pituitary are functioning normally, but there is a defect in the spermatogenic process and sperm are simply not being produced. Since the reproductive ductal structures are present and patent, both of the first two etiologies fall into the subclass of 'non-obstructive azoospermia'. Causes of 'primary' testicular failure include autosomal and Y chromosomal genetic aberrations, as well as numerous, putative genetic anomalies affecting the complex process of spermatogenesis. Chemotherapy and radiotherapy may also negatively and permanently affect spermatogenesis. 'Posttesticular' azoospermia is the result of a blockage to sperm flow at any level of the transport system, from rete testis to ejaculatory ducts and would constitute the subclass of 'obstructive azoospermia'.

The second way to think about the etiology of the azoospermia in a patient is a very practical one based upon two other important parameters of the semen analysis_-volume and $\mathrm{pH}$. There are three main contributors to the ejaculate fluid. ${ }^{4}$ The sperm containing effluent from the testis travels through the vas deferens, into its ampullary portion and finally through its ipsilateral ejaculatory duct. ${ }^{5}$ This comprises approximately $10 \%$ of the final semen volume. The seminal vesicles discharge their alkaline contents into the prostatic urethra via the paired ejaculatory ducts as well, their combined contribution making up about $70 \%$ of the ejaculate. Within the ejaculate fluid, all of the alkalinity comes from the seminal vesicles, and, obviously, is the 
vast majority of the volume. Finally, the prostate delivers about $20 \%$ of the fluid and is acidic in nature. The alkalinity of the seminal vesicle fluid overwhelms the acidity of the prostatic fluid and, hence, the normal ejaculate is alkaline in nature. Therefore, a very clinically focused way in which to begin thinking etiologically is to consider the volume and $\mathrm{pH}$ and classify the azoospermia as either 'low volume, low $\mathrm{pH}$ ' or 'normal volume, normal pH' (Figure 1). Low-volume, low-pH semen specimens consist only of prostatic fluid (approximately $0.6 \mathrm{ml}$ with a $\mathrm{pH}$ of 6.5 ). The seminal vesicles are either absent, as occurs in congenital bilateral absence of the vas deferens (CBAVD), or are present but blocked by occlusion of the ejaculatory ducts bilaterally and so do not contribute the amount or alkalinity as they normally do. Therefore, in the low-volume, low-pH azoospermic male, the diagnosis is typically either CBAVD (the seminal vesicles are either absent or aplastic) or bilateral ejaculatory duct obstruction (the seminal vesicles are normal but cannot deliver their contents due to occlusion of the ejaculatory ducts) (Figure 2).

In the azoospermic patient, if the semen volume is normal $(>1 \mathrm{ml})$ and alkaline $(\mathrm{pH}>7.0)$, the seminal vesicles are indeed functional and emptying through patent ejaculatory ducts. CBAVD and ejaculatory duct obstruction will not be diagnostic possibilities. In these cases, either there exists a blockage to sperm flow closer to the testes (the vas deferens or the epididymis) or the testes do not produce sperm (spermatogenic failure).

Whichever algorithmic approach is used, history, physical examination, and, on occasion, hormonal and other assorted assays and tests are critically important aids in the formulation and determination of the diagnosis.

If the patient has normal volume azoospermia secondary to spermatogenic failure (non-obstructive azoospermia (NOA)), two separate centrifuged semen analyses should be performed and the pellet examined microscopically for the presence of any spermatozoa. As reported by Jaffe et al., ${ }^{6} 21 \%$ of men were found to have miniscule numbers of motile sperm present in the pellet of their centrifuged ejaculate. The finding of any sperm in the semen analysis may dramatically change the potential diagnoses and possibilities. For example, the patient will not have a karyotype of 46,XX or have an $A Z F b / c$ microdeletion (see below). The patient will not have a complete blockage within the ductal system; the patient will not have CBAVD. In addition, these spermatozoa may be able to be cryopreserved to not only serve as a back-up source of sperm for a cycle of ICSI in the event when there is no useable sperm in the fresh ejaculate that morning but also to possibly preserve future fertility and biological paternity.

\section{THE MEDICAL AND SURGICAL HISTORY: WHAT CLUES MIGHT IT REVEAL?}

History begins with queries pertaining to present and past fertility, frequency and timing of sexual relations, and duration of infertility. Pediatric disorders such as cryptorchidism, viral orchitis or testicular torsion are important historical items to elicit. It is useful to be aware of medication usage and other medical conditions that presently exist.

Cryptorchidism is present in $1 \%-3 \%$ of newborns and adult infertility is a well-known long-term consequence. ${ }^{7,8}$ Although orchidopexy has a $90 \%$ successful outcome in palpable testes and even an $85 \%$ surgical success rate in abdominal testes, consequent infertility is still prevalent, although less when the orchidopexy is performed at a younger age. ${ }^{9-11}$ As reviewed by Hadziselimovic et al., ${ }^{12}$ azoospermia may be found in $10 \%$ and $32 \%$ of unilateral and bilateral cryptorchid patients, respectively. A critical event is the early postnatal 'minipuberty' at which time there is an increase in pituitary elaboration of gonadotropins, a resultant rise in Leydig cell testosterone secretion and a differentiation of gonocytes into Ad spermatogonia, a process that appears to be required to optimize adult spermatogenesis. In those for whom this minipuberty is blunted or non-existent, the risk of being azoospermic in adulthood is high. ${ }^{12}$ Hadziselimovic et al. ${ }^{13}$ has demonstrated that EGR4 is a critical, master gene of sorts responsible for the regulation of $\mathrm{LH}$ secretion and, as such, for the initiation of the minipuberty. Therefore, cryptorchidism, either unilateral or bilateral, whether corrected early or later, is an important risk factor for azoospermia. Obviously, this azoospermia would be non-obstructive ('testicular' or 'normal volume').

Testicular torsion occurs in approximately $0.025 \%$ of males prior to age of 25 years. ${ }^{14}$ Although unilateral testicular torsion does not lead to many alterations in semen parameters when compared to controls, if orchiectomy was performed, an additional problem may occur in the contralateral testis such as an obstructive epididymitis or vasal occlusion secondary to hernia repair. ${ }^{15-17}$

Obstruction of the ductal system may have a congenital, iatrogenic or acquired cause with vasectomy being the most common. It has been estimated that up to $40 \%$ of men with azoospermia will have an obstructive etiology. ${ }^{18}$ However, epididymal blockage is not uncommonly found, due to either clinically obvious or clinically unrecognized epididymitis and, on rare occasions, due to Young's syndrome. ${ }^{19-21}$ Prior hernia repair or pelvic surgery may be the inciting event in vasal injury. The histories, therefore, of epididymitis, hernia repair, scrotal surgery, chronic bronchitis, etc. all are clues to potential vasal or
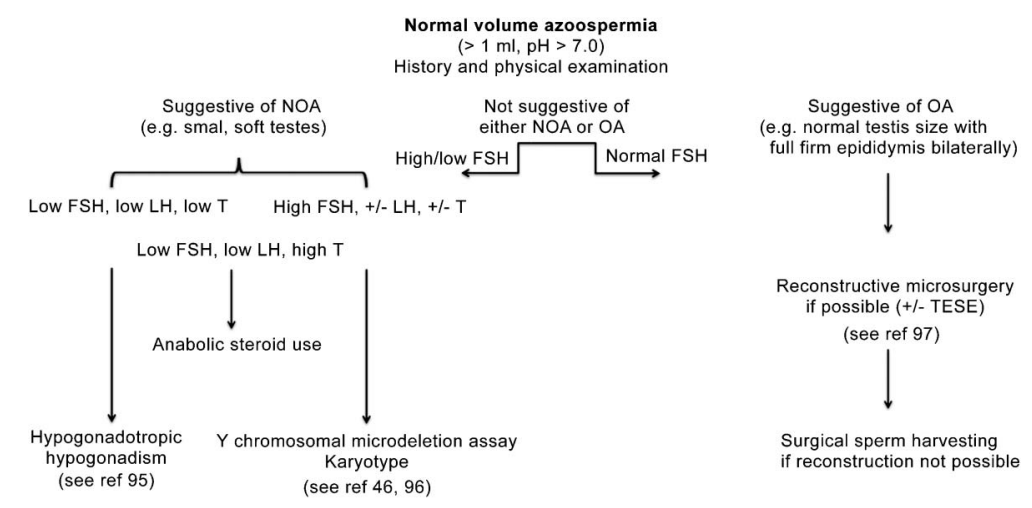

Figure 1 Algorithm for the Work-Up of Normal Volume Azoospermia. ${ }^{46,95-97}$ Beginning with the history and the physical examination, one can often determine if the azoospermia is non-obstructive (spermatogenic failure) or obstructive (normal spermatogenesis with a blockage of the ductal system). Occasionally, the history and/or physical examination is equivocal and hormonal studies (specifically FSH) may be helpful in directing the next steps. FSH, follicle-stimulating hormone; LH, luteinizing hormone; NOA, non-obstructive azoospermia; OA, obstructive azoospermia; TESE, testicular sperm extraction. 


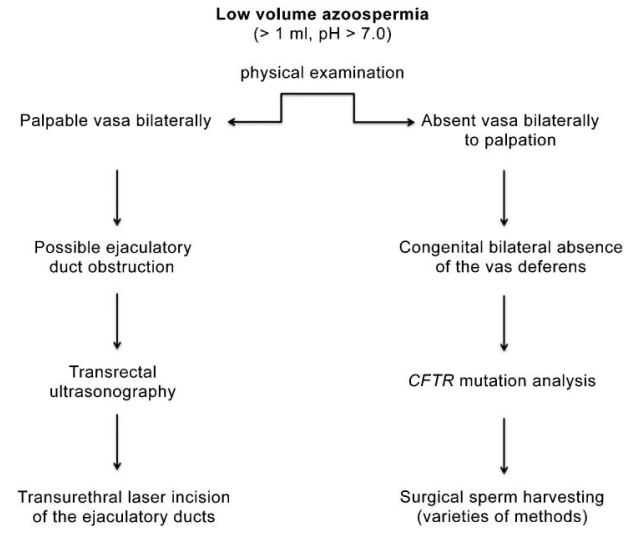

Figure 2 Algorithm for the Work-Up of Low Volume Azoospermia. The physical examination is the key to diagnosis in the male with a low volume, acidic $\mathrm{pH}$, azoospermic semen analysis. If the vasa deferentia are not palpable, Congenital Absence of the Vas Deferens is the diagnosis. If the vasa deferentia are palpable, most likely the diagnosis will be bilateral ejaculatory duct obstruction. The next step in diagnosis would be transrectal ultrasonography. CFTR, cystic fibrosis transmembrane conductance regulator.

epididymal obstruction. It is critically important for these men to have the proper diagnosis determined as microsurgical reconstruction is quite successful in specific cases in restoring natural fertility to these couples. ${ }^{22}$ Sperm aspiration and advanced reproductive techniques should not be the first option if reconstruction is possible and costeffective. $^{23}$

Anabolic steroid use is on the rise and it is necessary to specifically ask the patient if he is using any type of illicit anabolic steroid compound or prescribed testosterone pharmaceutical (reviewed elegantly by de Souza and $\mathrm{Hallak}^{24}$ ). It is not just the athletes and body builders that are of concern as testosterone supplementation as treatment for several nebulous indications (under the umbrella of 'hypogonadism') is being dispensed to men of all ages. ${ }^{25,26}$ For spermatogenesis to occur, testosterone must be synthesized locally and secreted by the Leydig cells. If exogenous androgenic compounds are circulating, they will act suppressively to pituitary elaboration of LH and, therefore, intratesticular testosterone production will be markedly reduced and spermatogenesis will be likewise impaired or abolished. ${ }^{27,28}$ Any history of prior anabolic steroid use for body building should be viewed as predictive of current use. When the serum testosterone level is high and FSH and LH are at very low, if not undetectable levels, anabolic steroid use is confirmed; however, it is worth noticing that the use of modified androgens (like nandrolone and stanzolol) may not result in elevated testosterone levels. Therefore, a patient must be asked specifically if he is taking testosterone or similar substances as they may not consider it a 'medication' as such.

Malignancy itself may have a detrimental, collateral, damaging effect on spermatogenesis, even to the point of azoospermia. Male oncology patients may have reduced reproductive hormone levels consequent to the stress and metabolic changes induced by the disease or to hypothalamic-pituitary downregulation due to substances secreted by the tumors themselves. ${ }^{29}$ In non-testis cancer, a reduction in sperm density may be found at the time of diagnosis but, as reported by van der Kaaij et al., ${ }^{30}$ in a group of young men with Hodgkin lymphoma, only $3 \%$ displayed azoospermia. Meguro et al. ${ }^{31}$ reported similarly encouraging news for 38 men suffering from a variety of hematological malignancies, including acute promyelocytic leukemia, acute lymphoblastic leukemia and non-Hodgkin lymphoma. None of them presented with azoospermia such that all had ejaculated spermatozoa cryopreserved prior to therapy. Even though the majority will have ejaculated spermatozoa to cryopreserve prior to any chemo or radiation therapy, sperm banking is not always offered. ${ }^{32}$ Finally, the observation that a history of cryptorchidism, micropenis (reflecting Leydig dysfunction), spermatogenic compromise and germ cell malignancy are seen to cluster in some men has led to the development of the 'testicular dysgenesis syndrome' hypothesis that suggests that a combination of genetic and environmental impacts during fetal life set up these reproductive dysfunctions in later life. Accordingly, it is not unusual to see men with such clinical history, especially azoospermia in a man with a history of cryptorchidism and/or testicular cancer. ${ }^{33,34} \mathrm{Up}$ to $20 \%$ of such men will be azoospermic at presentation. ${ }^{35-37}$ In patients with a previously treated malignancy, the exact chemotherapeutic agents used, the number of cycles that were needed and whether radiation was also required are important determinants of the long-term spermatogenic potential. ${ }^{38}$ After alkylating agent use, many men are left permanently azoospermic. ${ }^{39}$

\section{THE PHYSICAL EXAMINATION: WHAT MIGHT OUR EYES AND HANDS TELL US?}

The appearance of the patient is where the physical examination begins. Is he too muscular, too developed, too fit—oftentimes the first clue to anabolic steroid use? On the opposite end of the spectrum, does he look undervirilized with scant beard growth and gynecomastiapossible evidence of Klinefelter's syndrome or a hypothalamic/pituitary abnormality? However, there is no single Klinefelter profile as 47,XXY men can present with any phenotype imaginable depending upon how much circulating testosterone they have, from completely hypogonadal to normally virilized. Are there physical anomalies that may suggest other systemic disorders that may be associated with azoospermia (abnormally short stature that accompanies some severe Y chromosomal anomalies)? Are there surgical scars in the lower abdomen from prior hernia/hydrocele repair, possibly with concomitant orchidopexy as well?

The genital examination focuses on the testes, ductal structures and spermatic cords. Are there two testes in normal, descended position? What is their size and consistency? The average size of the adult testis ranges between 15 and $25 \mathrm{ml}$, the vast majority of which consists of the seminiferous tubules. ${ }^{40}$ When spermatogenesis is reduced, the size of each testis is likewise diminished as each seminiferous tubule shrinks or is not even present. Small or atrophic testes are, therefore, highly suggestive of spermatogenic impairment in the azoospermic male. However, testes of normal size and consistency may be found in those azoospermic men with obstructive pathologies. The epididymis typically feels fairly flat and nondescript, and slightly more prominent in the caput and cauda regions. When an obstructive process occurs downstream, the epididymis distends and feels more full and firm as may occur if the male has had a prior vasectomy, hernia repair that occludes the vas in the inguinal region, or an inflammatory epididymitis that leads to blockage of the epididymal tubule, often at the vasal/ epididymal junction. ${ }^{22}$ The vas deferens is easily palpable as it comes up vertically to enter the body at the external ring. The diagnosis of CBAVD is made easily on physical examination-non-palpable vasa in the setting of low-volume, low-pH azoospermia (the seminal vesicles are absent or atrophic in CBAVD). ${ }^{41}$ The testes are of adequate size and the epididymal remnants consist of (at the very least) a distended, easily palpable caput, although the epididymal remnant may actually consist of caput, corpus and even cauda, on occasion. The spermatic cords may reveal a large varicocele, which may be the proximate cause of non-obstructive azoospermia. ${ }^{42}$ 
Therefore, careful and attentive palpation of the scrotal contents, coupled with a well-done history, allows one to oftentimes make a complete diagnosis, or at least determine whether the azoospermia is non-obstructive or obstructive in nature. The details of testis size and consistency, vasal presence or absence, epididymal fullness or not, presence of a varicocele, etc. are not to be underemphasized. History and physical lead to a targeted approach for any of the adjunctive tests that may be helpful. For example, when CBAVD is determined by careful physical examination, a Y chromosomal microdeletion assay and karyotype do not need to be performed. When the vasa are easily palpable and the testis size is small and their consistency is soft in the setting of normal semen volume azoospermia, a cystic fibrosis mutation analysis does not need to be obtained.

\section{HORMONAL STUDIES: WHICH ONES SHOULD BE ORDERED AND HOW DO THEY HELP US?}

Hormonal assays are often, but certainly not always, helpful. Briefly, via stimulation from gonadotropin-releasing hormone, the pituitary elaborates FSH and LH. FSH is regulated by inhibin B which is secreted by Sertoli cells. As spermatogenesis decreases, inhibin B levels decrease, inhibition of FSH release decreases, and FSH output rises steadily in compensatory fashion. ${ }^{43}$ Therefore, there is no single value for FSH below which spermatogenesis is normal and above which spermatogenesis is abnormal. The value of FSH detected when spermatogenesis is optimal and adequate always resides in the lower end of the 'reference range' that is quoted for each assay. It is important to be aware that the reference ranges of commercial kits are not based on the analysis of normozoospermic fertile men, but on the general population with different reproductive and age characteristics. The most accurate 'normal' value is based on the median FSH levels measured in normozoospermic men and corresponds to $1.5-8 \mathrm{IU} \mathrm{l}^{-1}$. As spermatogenesis deteriorates and Sertoli cell output of inhibin wanes, there is a compensatory rise in pituitary elaboration of FSH such that the serum value ascends above the lower aspect of the 'reference range'. In other words, in order to conclude that azoospermia is secondary to spermatogenic compromise, the precise value of measured FSH does not need to 'exceed the upper limits of normal'. ${ }^{44,45}$ It is only in unclear circumstances (history and physical examination findings are not convincing) that the measurement of FSH is of assistance in delineating whether the azoospermia is non-obstructive or obstructive.

Testosterone and LH levels can be quantified as well but usually do not help in diagnosis. In conjunction with the final diagnosis, they may help provide a prognosis or simply allow for plans to be made for ultimate management if the LH is high and the testosterone is low. In specific cases of hypogonadotropic hypogonadism, the diagnosis can only be made with the realization that these values demonstrate hypothalamic or pituitary dysfunction (see Bonomi et al. in this special issue ${ }^{46}$ ).

\section{GENETIC STUDIES: WHICH ONES SHOULD BE ORDERED AND HOW DO THEY HELP US?}

A Y chromosomal microdeletion assay and a karyotype are the two most common genetic analyses required in the evaluation of the NOA male who has no obvious causal history. The exact molecular geography of nearly the entirety of the $\mathrm{Y}$ chromosome was elusive for many years. Within this fascinating structure exist eight palindromic stretches on Yq (P8- P1) ${ }^{47-51}$ (elegantly reviewed by Krausz et al. ${ }^{47}$ and Navarro-Costa et al. ${ }^{49}$; Ref. 51 is in this special issue by Tamburrino et al.). Each palindrome is constructed from repetitive building blocks termed amplicons. Identical amplicons distant from each other occasionally undergo non-allelic homologous recombination (NAHR; intrachromosomal recombination between homologous repetitive sequences) which may lead to deletion of different length pieces of Yq. ${ }^{52,53}$ Interspersed throughout this expanse of Yq are multiple genes felt to be crucial in the workings of the complex genetic mechanism of spermatogenesis. ${ }^{50,54,55}$

Within the stretch of Yq from palindrome P5 to P1, several NAHR microdeletion events occur. Some result in quantitatively absolute spermatogenic failure, while others have little, if any, effect on sperm production this $\mathrm{P} 5-\mathrm{P} 1$ palindromic stretch, and there are multiple aberrant NAHR microdeletion possibilities. Some result in spermatogenic failure, while others appear to have no effect on spermatogenesis. ${ }^{54,56}$ A Y chromosomal microdeletion assay (a PCR-based, peripheral blood test) defines these microdeletion possibilities. ${ }^{57,58}$ Clinically recognized possibilities are: $A Z F b$ (P5/proximal P1; $6.2 \mathrm{Mb}$ in length), $\mathrm{P} 4 /$ distal $\mathrm{P} 1$ (7.0 Mb in length), $A Z F c$ (b2/b4; $3.5 \mathrm{Mb}$ in length) and $A Z F b / c$ (P5/distal P1; $7.7 \mathrm{Mb}$ in length). ${ }^{51}$ In the NOA male, the frequency of occurrence for each is approximately: $\sim 1 \%$ $(A Z F b), \sim 1 \%(A Z F b / c)$ and $\sim 10 \%(A Z F c) .{ }^{59}$ Finally, a microdeletion within the $A Z F c$ region occurs as well and is termed $\mathrm{gr} / \mathrm{gr}$. It is commonly found in the azoospermic male but is certainly considered a risk factor for spermatogenic compromise. ${ }^{49,60,61}$ The most proximal region is the $A Z F a$ region. NAHR may also lead to a $0.8 \mathrm{Mb}$ microdeletion in approximately $1 \%$ of men with NOA and is detected on $\mathrm{Y}$ chromosomal microdeletion assay. ${ }^{62-64}$ Partial deletions involving only USP9Y (and not DDX3Y; USP9Y and DDX3Y are the two testis specific genes within the $A Z F a$ region) may occur and still allow spermatogenesis to occur. ${ }^{65}$ Briefly, for the NOA patient, if an $A Z F a, A Z F b$ or $A Z F b / c$ microdeletion is discovered, there is little likelihood, if any, of spermatozoa being harvested from the testis tissue. ${ }^{59,66-69}$

When an $A Z F c$ microdeletion is detected in the NOA male, up to $70 \%$ will have retrievable spermatozoa from the testis tissue while $30 \%$ will have no sperm found. ${ }^{68,70,71}$ If present, these sperm are fully capable of fertilization, embryo development and term pregnancy when utilized in conjunction with ICSI. ${ }^{72-74}$ All sons conceived, however, will inherit the $A Z F c$ microdeleted $\mathrm{Y}$ chromosome and will be predicted to display severe oligospermia, azoospermia with recoverable sperm in the testis tissue or azoospermia with no recoverable sperm in the testis tissue when reaching reproductive age. ${ }^{71}$

Of concern is the work of Jorgez et al., ${ }^{75}$ who reported copy number variations in the pseudoautosomal regions (X-Y homologous regions on the distal aspect of the short and the long arm of each of these two chromosomes) in men with Y chromosomal microdeletions of various types. Therefore, transmission of an $A Z F c$ microdeletion to all conceived sons may carry with it more than just the hardship of spermatogenic failure but also manifestations such as short stature due to haploinsufficiency of SHOX (short stature homeobox) ${ }^{76-78}$ Given its clinical relevance, this preliminary data need to be confirmed in future studies.

In the unexplained NOA patient, it is mandatory to also obtain a karyotypic analysis as the prevalence of chromosomal anomalies in these men is approximately $10 \%-15 \% .^{70,79}$ (fully reviewed in Ref. 80 in this special issue by Harton and Tempest). Aberrations such as 47,XXY Klinefelter's syndrome, 46,XX testicular disorder of sex development, isodicentric $\mathrm{Y}$ chromosomes, and translocations (balanced and Robertsonian) may all be detected and be the proximate cause of the spermatogenic compromise (fully reviewed in Ref. 80). ${ }^{81-85}$ Choice of therapy is determined by these types of findings. For example, there will be no sperm present in the testes of male with 46,XX testicular disorder of sex development and so any surgical search is unwarranted. However, if sperm are found in the testes of men with translocations, preimplantation diagnosis 
can be employed to improve the chances of a normal, healthy pregnancy.

Cystic fibrosis mutation analysis is required in all men with CBAVD and their partners. CBAVD is found in approximately $2 \%-3 \%$ of infertile Caucasian males. ${ }^{70}$ Sperm production is normal, but the majority of the proximal and distal ductal system (corpus and cauda epididymis, vasa deferentia, seminal vesicles) is absent. As above, because the seminal vesicles are absent or atrophic, the ejaculate consists only of a low volume of acidic prostatic fluid. ${ }^{86} \mathrm{CBAVD}$ is an easy diagnosis to make with a combination of physical examination and consideration of the semen volume and $\mathrm{pH}$. In $90 \%$ of cases, CBAVD is a phenotypic, collateral consequence of quantitative or qualitative defects in cystic fibrosis transmembrane conductance regulator (CFTR) gene. ${ }^{87,88}$ CFTR is the protein product of the cystic fibrosis gene (7q31.2). ${ }^{89}$ The clinical expression of disease depends upon the exact nature of the combination of maternally and paternally inherited mutations. ${ }^{41,90}$ If both mutations are 'severe', clinical cystic fibrosis may be manifest (pulmonary and pancreatic dysfunction, vasal absence if male). If either of the mutations (or both) is 'mild', then perhaps the pulmonary and pancreatic systems will appear clinically unaffected, but vasal absence will still be present (CBAVD).$^{91}$ Obviously, the patient may present anywhere along the spectrum, and be bookended by those two clinical entities. It is critical to also perform partner cystic fibrosis mutation analysis. ${ }^{92}$ Such analysis does not eliminate the risk because, at present, it is impossible to test all 1200 known mutations, but this risk can be reduced to a level acceptable to patients. In the event she is a carrier for a CFTR mutation, preimplantation genetic analysis of the embryos would be recommended to avoid transferring an embryo that has inherited her mutation as well as one of that two the male carries, as the offspring would be expected to present with CFTR related disease, the exact severity of which would be dependent upon the mutation combination inherited. ${ }^{93}$

As described by McCallum et al. ${ }^{94}$ a small percentage of CBAVD men do not have CFTR mutations as their underlying genetic etiology and have, in addition, unilateral renal agenesis. These men probably possess an unknown genetic anomaly affecting mesonephric duct development (the progenitor of both the reproductive ductal and ureteral derivatives). Important for the patient to understand is that he has only a solitary renal unit. Although it appears to be unlikely, it is important for the couple to realize that bilateral renal agenesis may affect a fetus/infant, as was documented by McCallum et al. ${ }^{94}$

\section{CONCLUSION}

In conclusion, simply a thorough history and a careful physical examination allow a precise diagnosis in azoospermic men to be made in the majority of cases. When coupled with adjunctive pieces of information, such as semen volume and $\mathrm{pH}, \mathrm{FSH}$, a Y chromosomal microdeletion assay, karyotype and cystic fibrosis mutation analysis, the underlying etiology, whether genetic in nature or acquired, is easy to be discovered. A targeted approach to testing is recommended so that only necessary studies are obtained. By using an algorithmic approach to diagnosis, a more intellectual path to diagnosis can be made.

\section{COMPETING FINANCIAL INTERESTS}

The author declares no competing financial interests.

1 ASRM Practice Committee. Evaluation of the azoospermic male. Fertil Steril 2008; 90: $574-7$
2 Sigman S, Lipshultz L, Howards S. Office evaluation of the subfertile male. In: Lipshultz L, Howards S, Niederberger C, editors. Infertility in the Male. 4th ed. New York: Cambridge University Press; 2009. pp153-76.

3 Krausz C. Male infertility: pathogenesis and clinical diagnosis. Best Pract Res Clin Endocrinol Metab 2011; 25: 271-85.

4 Turner T. The epididymis and accessory sex organs. In: Lipshultz L, Howards S, Niederberger C, editors. Infertility in the Male. 4th ed. New York: Cambridge University Press; 2009. pp90-103.

5 Lewis J, Kaplan W. Anatomy and embryology of the male reproductive tract and gonadal development. In: Lipshultz L, Howards S, Niederberger C, editors. Infertility in the Male. 4th ed. New York: Cambridge University Press; 2009. pp1-13.

6 Jaffe TM, Kim ED, Hoekstra TH, Lipshultz LI. Sperm pellet analysis: a technique to detect the presence of sperm in men considered to have azoospermia by routine semen analysis. J Urol 1998; 159: 1548-50.

7 Chung E, Brock GB. Cryptorchidism and its impact on male fertility: a state of art review of current literature. Can Urol Assoc J 2011; 5: 210-4.

8 Kolon TF, Patel RP, Huff DS. Cryptorchidism: diagnosis, treatment, and long-term prognosis. Urol Clin N Am 2004; 31: 496-80, viii-ix.

9 Canavese F, Mussa A, Manenti M, Cortese MG, Ferrero L et al. Sperm count of young men surgically treated for cryptorchidism in the first and second year of life: fertility is better in children treated at a younger age. Eur J Pediatr Surg 2009; 19: 388-91.

10 Thorup J, Cortes D. Surgical treatment and follow up on undescended testis. Pediatr Endocrinol Rev 2009; 7: 38-43.

11 Trsinar B, Muravec UR. Fertility potential after unilateral and bilateral orchidopexy for cryptorchidism. World J Urol 2009; 27: 513-9.

12 Hadziselimovic F, Hadziselimovic NO, Demougin P, Oakeley EJ. Testicular gene expression in cryptorchid boys at risk of azoospermia. Sex Dev 2011; 5: 49-59.

13 Hadziselimovic F, Hadziselimovic NO, Demougin P, Krey G, Hoecht B et al. EGR4 is a master gene responsible for fertility in cryptorchidism. Sex Dev 2009; 3: 253-63.

14 Williamson RC. Torsion of the testis and allied conditions. Br J Surg 1976; 63: 465-76.

15 Anderson MJ, Dunn JK, Lipshultz LI, Coburn M. Semen quality and endocrine parameters after acute testicular torsion. J Urol 1992; 147: 1545-50.

16 Arap MA, Vicentini FC, Cocuzza M, Hallak J, Athayde K et al. Late hormonal levels, semen parameters, and presence of antisperm antibodies in patients treated for testicular torsion. J Androl 2007; 28: 528-32.

17 Romeo C, Impellizzeri P, Arrigo T, Antonuccio P, Valenzise M et al. Late hormonal function after testicular torsion. J Pediatr Surg 2010; 45: 411-3.

18 Jarow JP, Espeland MA, Lipshultz LI. Evaluation of the azoospermic patient. J Urol 1989; 142: 62-5

19 Domingo C, Mirapeix RM, Encabo B, Roig J, Lopez D et al. Clinical features and ultrastructure of primary ciliary dyskinesia and Young syndrome. Rev Clin Esp 1997; 197: 100-3.Spanish

20 Kim ED, Winkel E, Orejuela F, Lipshultz LI. Pathological epididymal obstruction unrelated to vasectomy: results with microsurgical reconstruction. J Urol 1998; 160: 2078-80.

21 Sheynkin YR, Hendin BN, Schlegel PN, Goldstein M. Microsurgical repair of iatrogenic injury to the vas deferens. J Urol 1998; 159: 139-41.

22 Tanrikut C, Goldstein M. Obstructive azoospermia: a microsurgical success story. Sem Reprod Med 2009; 27: 159-64.

23 Kolettis PN, Thomas AJ Jr. Vasoepididymostomy for vasectomy reversal: a critical assessment in the era of intracytoplasmic sperm injection. J Urol 1997; 158: 467-70.

24 de Souza GL, Hallak J. Anabolic steroids and male infertility: a comprehensive review. BJU Int, 2011; 108: 1860-5.

25 Margo K, Winn R. Testosterone treatments: why, when, and how? Am Fam Physician 2006; 73: 1591-8.

26 Weintraub A. Testosterone is sure looking virile. Bloomberg Bus Week 2009; 4154: 00077135

27 Dohle GR, Smit M, Weber RF. Androgens and male fertility. World J Urol 2003; 21 : 341-5.

28 Lombardo F, Sgro P, Salacone P, Gilio B, Gandini L et al. Androgens and fertility. J Endocrinol Invest 2005; 28: 51-5.

29 Dohle GR. Male infertility in cancer patients: review of the literature. Int J Urol 2010; 17: 327-31.

30 van der Kaaij MA, Heutte N, van Echten-Arends J, Raemaekers JM, Carde P et al. Sperm quality before treatment in patients with early stage Hodgkin's lymphoma enrolled in EORTC-GELA Lymphoma Group trials. Haematologica 2009; 94: 1691-7.

31 Meguro A, Muroi K, Miyoshi T, Matsuyama T, Mori M et al. Sperm cryopreservation in patients with hematologic malignancies. Int J Hematol 2008; 88: 351-4.

32 Amirjannati N, Sadeghi M, Hosseini Jadda SH, Ranjbar F, Kamali K et al. Evaluation of semen quality in patients with malignancies referred for sperm banking before cancer treatment. Andrologia 2011; 43: 317-20.

33 Jorgensen N, Meyts ER, Main KM, Skakkebaek NE. Testicular dysgenesis syndrome comprises some but not all cases of hypospadias and impaired spermatogenesis. Int J Androl 2010; 33: 298-303.

34 Toppari J, Virtanen HE, Main KM, Skakkebaek NE. Cryptorchidism and hypospadias as a sign of testicular dysgenesis syndrome (TDS): environmental connection. Birth Defects Res A Clin Mol Teratol 2010; 88: 910-9.

35 Fossa SD, Klepp 0, Molne K, Aakvaag A. Testicular function after unilateral orchiectomy for cancer and before further treatment. Int J Androl 1982; 5: 179-84.

36 Liguori G, Trombetta C, Bucci S, Benvenuto S, Amodeo A et al. Semen quality before and after orchiectomy in men with testicular cancer. Arch Ital Urol Androl 2008; 80: 99-102. 
37 Petersen PM, Skakkebaek NE, Vistisen K, Rorth M, Giwercman A. Semen quality and reproductive hormones before orchiectomy in men with testicular cancer. $J$ Clin Oncol 1999; 17: 941-7.

38 Naysmith TE, Blake DA, Harvey VJ, Johnson NP. Do men undergoing sterilizing cancer treatments have a fertile future? Hum Reprod 1998; 13: 3250-5.

39 Williams DH. Sperm banking and the cancer patient. Ther Adv Urol 2010; 2: 19-34.

40 Chipkevitch E, Nishimura RT, Tu DG, Galea-Rojas M. Clinical measurement of testicular volume in adolescents: comparison of the reliability of 5 methods. J Urol 1996; 156: 2050-3.

41 Oates RD, Amos JA. The genetic basis of congenital bilateral absence of the vas deferens and cystic fibrosis. J Androl 1994; 15: 1-8.

42 Weedin JW, Khera M, Lipshultz LI. Varicocele repair in patients with nonobstructive azoospermia: a meta-analysis. J Urol 2010; 183: 2309-15.

43 Sokol R. Endocrine evaluation. In: Lipshultz L, Howards S, Niederberger C, editors Infertility in the Male. 4th ed. New York: Cambridge University Press; 2009. pp199-214.

44 Chen SC, Hsieh JT, Yu HJ, Chang HC. Appropriate cut-off value for follicle-stimulating hormone in azoospermia to predict spermatogenesis. Reprod Biol Endocrinol 2010; 8: 108 .

45 Madani AH, Falahatkar S, Heidarzadeh A, Roshan ZA, Sazgari E et al. Sensitivity and specificity of serum $\mathrm{FSH}$ and testis size in predicting the existence of spermatogenesis in azoospermic infertile men. Andrologia; e-pub ahead of print 25 July 2011; doi: 10.1111/j.1439-0272.2010.01130.x.

46 Bonomi M, Libri DV, Guizzardi F, Guarducci E, Maiolo E et al. The Idiopathic Central Hypogonadism Study Group of the Italian Societies of Endocrinology and Pediatric Endocrinology and Diabetes. New understandings of the genetic basis of isolated idiopathic central hypogonadism. Asian J Androl 2012; 14: 49-56.

47 Krausz C, Chianese C, Giachini C, Guarducci E, Laface I et al. The Y chromosome-linked copy number variations and male fertility. J Endocrinol Invest 2011; 34: 376-82.

48 Kuroda-Kawaguchi T, Skaletsky H, Brown LG, Minx PJ, Cordum HS et al. The AZFc region of the $Y$ chromosome features massive palindromes and uniform recurrent deletions in infertile men. Nat Genet 2001; 29: 279-86.

49 Navarro-Costa P, Plancha CE, Goncalves J. Genetic dissection of the AZF regions of the human Y chromosome: thriller or filler for male (in)fertility? J Biome Biotechnol 2010; 2010: 936569

50 Skaletsky H, Kuroda-Kawaguchi T, Minx PJ, Cordum HS, Hillier L et al. The malespecific region of the human $\mathrm{Y}$ chromosome is a mosaic of discrete sequence classes. Nature 2003; 423: 825-37.

51 Tamburrino L, Marchiani S, Montoya M, Marino FE, Natali I et al. Mechanisms and clinical correlates of sperm DNA damage. Asian J Androl 2012; 14: 24-31.

52 Reijo R, Lee TY, Salo P, Alagappan R, Brown LG et al. Diverse spermatogenic defects in humans caused by $Y$ chromosome deletions encompassing a novel RNA-binding protein gene. Nat Genet 1995; 10: 383-93.

53 Repping S, Skaletsky H, Lange J, Silber S, van der Veen F et al. Recombination between palindromes $\mathrm{P} 5$ and $\mathrm{P} 1$ on the human $\mathrm{Y}$ chromosome causes massive deletions and spermatogenic failure. Am J Hum Genet 2002; 71: 906-22.

54 Vogt PH. AZF deletions and Y chromosomal haplogroups: history and update based on sequence. Hum Reprod Update 2005; 11: 319-36.

55 Vogt PH, Fernandes S. Polymorphic $D A Z$ gene family in polymorphic structure of AZFc locus: artwork or functional for human spermatogenesis? APMIS2003; 111: 115-26; discussion 26-7

56 Krausz C, Degl'Innocenti S. Y chromosome and male infertility: update, 2006. Front Biosci 2006; 11: 3049-61.

57 Simoni M, Bakker E, Krausz C. EAA/EMQN best practice guidelines for molecular diagnosis of Y-chromosomal microdeletions. State of the art 2004. Int J Androl 2004; 27: 240-9.

58 Viswambharan N, Suganthi R, Simon AM, Manonayaki S. Male infertility: polymerase chain reaction-based deletion mapping of genes on the human chromosome. Singapore Med J 2007; 48: 1140-2.

59 Simoni M, Tuttelmann F, Gromoll J, Nieschlag E. Clinical consequences of microdeletions of the $Y$ chromosome: the extended Munster experience. Reprod Biomed Online 2008; 16: 289-303.

60 Krausz C, Giachini C, Xue Y, O'Bryan MK, Gromoll J et al. Phenotypic variation within European carriers of the $\mathrm{Y}$-chromosomal gr/gr deletion is independent of $\mathrm{Y}$ chromosomal background. J Med Genet 2009; 46: 21-31.

61 Noordam MJ, Westerveld GH, Hovingh SE, van Daalen SK, Korver CM et al. Gene copy number reduction in the azoospermia factor $\mathrm{C}(\mathrm{AZFC})$ region and its effect on total motile sperm count. Hum Mol Genet 2011; 20: 2457-63.

62 Kamp C, Hirschmann P, Voss H, Huellen K, Vogt PH. Two long homologous retroviral sequence blocks in proximal Yq11 cause AZFa microdeletions as a result of intrachromosomal recombination events. Hum Mol Genet 2000; 9: 2563-72.

63 Rauschendorf MA, Zimmer J, Hanstein R, Dickemann C, Vogt PH. Complex transcriptional control of the AZFa gene DDX3Y in human testis. Int J Androl 2011; 34: 84-96.

64 Sun C, Skaletsky H, Rozen S, Gromoll J, Nieschlag E et al. Deletion of azoospermia factor a (AZFa) region of human $Y$ chromosome caused by recombination between HERV15 proviruses. Hum Mol Genet 2000; 9: 2291-6.

65 Krausz C, Degl'Innocenti S, Nuti F, Morelli A, Felici F et al. Natural transmission of USP9Y gene mutations: a new perspective on the role of AZFa genes in male fertility. Hum Mol Genet 2006; 15: 2673-81.

66 Costa P, Goncalves R, Ferras C, Fernandes S, Fernandes AT et al. Identification of new breakpoints in AZFb and AZFc. Mol Hum Reprod 2008; 14: 251-8.

67 Hopps CV, Mielnik A, Goldstein M, Palermo GD, Rosenwaks Z et al. Detection of sperm in men with $\mathrm{Y}$ chromosome microdeletions of the AZFa, AZFb and AZFc regions. Hum Reprod 2003; 18: 1660-5.
68 Patrat C, Bienvenu T, Janny L, Faure AK, Fauque P et al. Clinical data and parenthood of 63 infertile and Y-microdeleted men. Fertil Steril 2010; 93: 822-32.

69 Stahl PJ, Masson P, Mielnik A, Marean MB, Schlegel PN et al. A decade of experience emphasizes that testing for $Y$ microdeletions is essential in American men with azoospermia and severe oligozoospermia. Fertil Steril 2010; 94: 1753-6.

70 Oates RD. Clinical evaluation of the infertile male with respect to genetic etiologies Syst Biol Reprod Med 2011; 57: 72-7.

71 Oates RD, Silber S, Brown LG, Page DC. Clinical characterization of 42 oligospermic or azoospermic men with microdeletion of the AZFc region of the $Y$ chromosome, and of 18 children conceived via ICSI. Hum Reprod 2002; 17: 2813-24.

72 Gambera L, Governini L, de Leo V, Luddi A, Morgante G et al. Successful multiple pregnancy achieved after transfer of frozen embryos obtained via intracytoplasmic sperm injection with testicular sperm from an AZFc-deleted man. Fertil Steril 2010; 94: 2330e1-3.

73 Mulhall JP, Reijo R, Alagappan R, Brown L, Page D et al. Azoospermic men with deletion of the DAZ gene cluster are capable of completing spermatogenesis: fertilization, normal embryonic development and pregnancy occur when retrieved testicular spermatozoa are used for intracytoplasmic sperm injection. Hum Reprod 1997; 12: 503-8.

74 Oates RD, Mulhall J, Burgess C, Cunningham D, Carson R. Fertilization and pregnancy using intentionally cryopreserved testicular tissue as the sperm source for intracytoplasmic sperm injection in 10 men with non-obstructive azoospermia. Hum Reprod 1997; 12: 734-9.

75 Jorgez CJ, Weedin JW, Sahin A, Tannour-Louet M, Han S et al. Aberrations in pseudoautosomal regions (PARs) found in infertile men with Y-chromosome microdeletions. J Clin Endocrinol Metab 2011; 96: E674-9.

76 Binder G. Short stature due to SHOX deficiency: genotype, phenotype, and therapy. Horm Res Paediatr 2011; 75: 81-9.

77 Mohandas TK, Speed RM, Passage MB, Yen PH, Chandley AC et al. Role of the pseudoautosomal region in sex-chromosome pairing during male meiosis: meiotic studies in a man with a deletion of distal Xp. Am J Hum Genet 1992; 51: 526-33.

78 Ross JL, Kowal K, Quigley CA, Blum WF, Cutler GB Jr et al. The phenotype of short stature homeobox gene (SHOX) deficiency in childhood: contrasting children with Leri-Weill dyschondrosteosis and Turner syndrome. J Pediatr 2005; 147: 499-507.

79 Oates RD. The genetic basis of male reproductive failure. Urol Clin N Am 2008; 35 257-70, ix.

80 Harton GL, Tempest HG. Chromosomal disorders and male infertility. Asian J Androl 2012; 14: 32-9.

81 Lange J, Skaletsky H, van Daalen SK, Embry SL, Korver CM et al. Isodicentric $\mathrm{Y}$ chromosomes and sex disorders as byproducts of homologous recombination that maintains palindromes. Cell 2009; 138: 855-69.

82 Lee JY, Dada R, Sabanegh E, Carpi A, Agarwal A. Role of genetics in azoospermia Urology 2010; 77: 598-601.

83 Martin RH. Cytogenetic determinants of male fertility. Hum Reprod Update 2008; 14 379-90.

84 Paduch DA, Fine RG, Bolyakov A, Kiper J. New concepts in Klinefelter syndrome. Curr Opin Urol 2008; 18: 621-7.

85 Vorona E, Zitzmann M, Gromoll J, Schuring AN, Nieschlag E. Clinical, endocrinologic and epigenetic features of the $46, \mathrm{XX}$ male syndrome compared to $47, \mathrm{XXY}$ Klinefelter patients. J Clin Endocrinol Metab 2007; 92: 3458-65.

86 Samli H, Samli MM, Yilmaz E, Imirzalioglu N. Clinical, andrological and genetic characteristics of patients with congenital bilateral absence of vas deferens (CBAVD). Arch Androl 2006; 52: 471-7.

87 Bareil C, Guittard C, Altieri JP, Templin C, Claustres M et al. Comprehensive and rapid genotyping of mutations and haplotypes in congenital bilateral absence of the vas deferens and other cystic fibrosis transmembrane conductance regulator-related disorders. J Mol Diagn 2007; 9: 582-8.

88 Walsh TJ, Pera RR, Turek PJ. The genetics of male infertility. Sem Reprod Med 2009, 27: 124-36.

89 Database CFM. http://www.genet.sickkids.on.ca/cftr.

90 Wilschanski M, Dupuis A, Ellis L, Jarvi K, Zielenski J et al. Mutations in the cystic fibrosis transmembrane regulator gene and in vivo transepithelial potentials. Am J Respir Crit Care Med 2006; 174: 787-94.

91 Ratbi I, Legendre M, Niel F, Martin J, Soufir JC et al. Detection of cystic fibrosis transmembrane conductance regulator (CFTR) gene rearrangements enriches the mutation spectrum in congenital bilateral absence of the vas deferens and impacts on genetic counselling. Hum Reprod 2007; 22: 1285-91.

92 Practice Committee of American Society for Reproductive Medicine in collaboration with Society for Male Reproduction and Urology. Evaluation of the azoospermic male Fertil Steril 2008; 90: S74-7

93 Tur-Kaspa I, Aljadeff G, Rechitsky S, Grotjan HE, Verlinsky Y. PGD for all cystic fibrosis carrier couples: novel strategy for preventive medicine and cost analysis. Reprod Biomed Online 2010; 21: 186-95

94 McCallum T, Milunsky J, Munarriz R, Carson R, Sadeghi-Nejad H etal. Unilateral renal agenesis associated with congenital bilateral absence of the vas deferens: phenotypic findings and genetic considerations. Hum Reprod 2001; 16: 282-8.

95 Wiener-Megnazi Z, Auslender R, Dirnfeld M. Advanced paternal age and reproductive outcome. Asian J Androl 2012; 14: 69-76.

96 Lopushnyan NA, Walsh TJ. Surgical techniques for the management of male infertility. Asian J Androl 2012; 14: 94-102.

97 Ramasamy R, Stahl PJ, Schlegel PN. Medical therapy for spermatogenic failure. Asian $J$ Androl 2012; 14: 57-60. 